\title{
Changes in the factor VIII complex in diabetic ketoacidosis: evidence of endothelial cell damage?
}

\author{
M. Greaves ${ }^{1}$, C. Pickering ${ }^{1}$, G. Knight ${ }^{2}$, A. J. M. Boulton ${ }^{2}$, J. Ball ${ }^{1}$, J.D. Ward ${ }^{2}$ and F. E. Preston ${ }^{1}$ \\ Departments of ${ }^{1}$ Haematology and ${ }^{2}$ Medicine, Royal Hallamshire Hospital, Sheffield, UK
}

\begin{abstract}
Summary. Factor VIII-related antigen and von Willebrand factor are synthesised by and released from vascular endothelium. Acute increases in the plasma concentration of these proteins may reflect endothelial cell damage. We have thus measured the plasma concentration of factor VIII-related antigen and von Willebrand factor, together with procoagulant factor VIII, during the course of acute diabetic ketoacidosis in seven patients. In addition, evidence for qualitative changes in the factor VIII complex was sought. Plasma factor VIII-related antigen and von Willebrand factor were markedly increased (plasma factor VIII-related antigen at presentation, median $2.75 \mathrm{U} / \mathrm{ml}$; von Willebrand factor $2.95 \mathrm{U} / \mathrm{ml}$ ) and returned toward normal with clinical and biochemical resolution (plasma factor VIII-related antigen at clinical recovery, median $1.80 \mathrm{U} / \mathrm{ml}$; von Willebrand factor $2.05 \mathrm{U} / \mathrm{ml}$ ). Plasma procoagulant factor VIII followed a similar pattern, but levels
\end{abstract}

were less elevated (plasma procoagulant factor VIII, at presentation, median $1.6 \mathrm{U} / \mathrm{ml}$; at clinical recovery, $1.2 \mathrm{U} / \mathrm{ml}$ ). Crossed immunoelectrophoresis and sodium dodecyl sulphate-acrylamide electrophoresis with autoradiographic identification of multimeric structure revealed no evidence of structurally abnormal factor VIII-related antigen in diabetic ketoacidosis. However, an extra peak on crossed immunoelectrophoresis ("pre-peak") was a feature in the acute phase ketoacidotic plasma in six subjects, and may represent aggregated factor VIII. Changes in plasma factor VIII are a feature of diabetic ketoacidosis and, whilst not specific to this condition, may be the result of endothelial cell damage.

Key words: Diabetes mellitus, factor VIII, ketoacidosis, endothelial damage, factor VIII multimers.
Factor VIII exists in plasma as a complex of proteins. The von Willebrand factor component (vWF) is of very high molecular weight, is synthesised by vascular endothelial cells and megakaryocytes and is necessary for platelet adhesion to subendothelial structures. It is a multimeric glycoprotein, only multimers of high molecular weight possessing von Willebrand factor activity, measurable by its ability to support ristocetin-induced platelet agglutination. The associated antigen (VIII: Ag) can be measured by a variety of immunological techniques. The procoagulant component of the factor VIII complex (VIII: C) is a cofactor for the activation of factor X, is antigenically distinct from VIII: $\mathrm{Ag}$ and is probably predominantly synthesised in the liver.

Increased plasma concentrations of the components of the factor VIII complex, especially VIII: $\mathrm{Ag}$ and vWF, have been described in diabetes mellitus [1-13]. There may be a relationship between the increase in factor VIII and duration of diabetes [2] and the presence of vascular complications $[1,4,12]$. Although the significance of these changes in the pathogenesis of vascular disease is unknown, increased plasma VIII: $\mathrm{Ag}$ and vWF may indicate the presence of endothelial cell damage [14].

Gross changes in the plasma concentration of plasma VIII: Ag have been described in severely ill subjects with acute respiratory failure and considered to relate to damage to the pulmonary vascular endothelium $[15,16]$. The profound metabolic disturbance which results from diabetic ketoacidosis may also result in endothelial cell damage. We have therefore studied serial qualitative and quantitative changes in the components of the factor VIII complex during episodes of ketoacidosis.

\section{Subjects and methods}

Observations were made on samples obtained during seven episodes of ketoacidosis in seven diabetic patients. Clinical details of the patients studied are given in Table 1 . In each case the serum bicarbonate concentration was $15 \mathrm{mmol} / 1$ or less at presentation (mean 10; range 6-15 mmol/1). Blood glucose was $34.2 \mathrm{mmol} / 1$ (range $23.8-51.7$ $\mathrm{mmol} / \mathrm{l})$. One subject had long-standing severe retinopathy and neu- 
Table 1. Clinical characteristics of patients

\begin{tabular}{|c|c|c|c|c|c|c|}
\hline Subject & $\begin{array}{l}\text { Age } \\
\text { (years) }\end{array}$ & $\begin{array}{l}\text { Duration of diabetes } \\
\text { (years) }\end{array}$ & $\begin{array}{l}\text { Renal } \\
\text { impairment }\end{array}$ & \multicolumn{3}{|c|}{ Vascular disease $^{\mathrm{a}}$} \\
\hline B & 22 & 11 & 0 & 0 & 0 & 0 \\
\hline $\mathrm{C}^{\mathrm{b}}$ & 51 & 29 & 0 & 0 & 0 & 0 \\
\hline D & 19 & 4 & 0 & 0 & 0 & 0 \\
\hline $\mathrm{G}$ & 19 & 15 & 0 & 0 & 0 & 0 \\
\hline
\end{tabular}

a Determined by urine examination for protein, serum creatinine, fundoscopy, clinical examination of peripheral pulses and sensorimotor function, nerve conduction velocity and vibration perception threshold ${ }^{b}{ }^{b}$ bronchopneumonia at presentation with ketoacidosis; ${ }^{c}$ Severe diabetic nephropathy, blindness and autonomic neuropathy

ropathy. The remainder had no clinical evidence of diabetic vascular disease (Table 1).

Blood for factor VIII studies was sampled at presentation and at convenient intervals thereafter (as part of the routine biochemical assessment and usually every $24 \mathrm{~h}$ ) until clinical and biochemical recovery, and again during convalescence. On each occasion, $10 \mathrm{ml}$ venous blood was drawn into a vacuum tube containing sodium citrate to give a final concentration in blood of $0.38 \%$. Plasma was separated immediately by centrifugation and frozen at $-20^{\circ} \mathrm{C}$ until analysed. Where necessary, serum was prepared from blood allowed to clot in glass at room temperature; after separation, serum was stored at $-20^{\circ} \mathrm{C}$. The protocol was given Hospital Ethical Committee approval.

Ketoacidotic episodes were managed conventionally by fluid and salt replacement and insulin by continuous intravenous infusion. All patients made a full clinical recovery.

Factor VIJI procoagulant (VIII: C) was assayed by a two-stage technique based upon the thromboplastin generation test [17].

The von Willebrand Factor(vWF) was measured using fixed, washed platelets and a platelet counting technique, after Evans and Austen [18].

Factor VIII-related antigen (VIII: Ag) was determined by two techniques. An immunoelectrophoretic method using a specific antibody was performed after Laurell [19], and an enzyme-linked immunosorbent assay (Elisa) was performed based upon the method of Short et al. [20].

Crossed immunoelectrophoresis of factor VIII: Ag was performed on plasma and serum samples using $1.0 \% \mathrm{w} / \mathrm{v}$ agarose in the first dimension and $1.0 \%$ agarose containing $0.75 \mu \mathrm{l} / \mathrm{ml}$ of anti-human factor VIII-related antigen antibody (Dakopatts, Surrey, UK) in the second dimension. A barbitone-acetate electrophoresis buffer, $\mathrm{pH} 8.6$ (Oxoid, Hampshire, UK) was used. Electrophoresis was performed at $38 \mathrm{v} / \mathrm{cm}$ at $10^{\circ} \mathrm{C}$ until a bromophenol blue marker had moved $4 \mathrm{~cm}$ into the agarose. Strips were then cut and reassembled at 90 degrees onto an $8 \times 8 \mathrm{~cm}$ glass plate. Antibody-containing agarose was added and electrophoresis (second dimension) carried out at $14 \mathrm{v} / \mathrm{cm}$ for $18 \mathrm{~h}$. Plates were then washed in saline overnight, squashed, dried and stained with Coomassie brilliant blue. An identical procedure was followed using antifibronectin antibody (prepared in rabbits). Selected samples were electrophoresed as above and subsequently processed for autoradiography following prolonged incubation in a bath containing ${ }^{125}$ I-anti-factor VIII-related antigen produced by a modification of the method of Reay [21, 22].

Factor VIII multimeric analysis was performed by a modification of the methods of Ruggeri and Zimmerman [23] and Enayat and Hill [24]. Briefly, plasma was diluted one part in ten in a tris-urea buffer $(10 \mathrm{mmol} / 1$ tris, $0.8 \mathrm{~m}$ urea; $\mathrm{pH} 8.0)$ containing $0.2 \%$ sodium dodecyl sulphate. Electrophoresis was through a sodium dodecyl sulphateacrylamide gel for $18 \mathrm{~h}$ at $0.3 \mathrm{~m} \mathrm{~A} / \mathrm{cm}$. Gels were then fixed, washed and dried prior to autoradiography as above.

\section{Results}

The plasma concentrations of factor VIII: C, VIII: Ag and VWF in 7 diabetic patients at presentation in diabetic ketoacidosis and at various timepoints during treatment are depicted in Figure 1. Plasma factor VIII: C was elevated in five patients at presentation but returned rapidly toward normal with treatment (1a). vWF was elevated in six patients, markedly so in five (1b). In most cases there was a return toward normal with treatment, although values remained elevated at a time of clinical and biochemical recovery in four cases (two at $48 \mathrm{~h}$, one at $96 \mathrm{~h}$ and one at $120 \mathrm{~h}$ ). The pattern of plasma VIII: Ag was similar, increased concentration being found at presentation with a tendency to a slow fall during treatment ( $1 \mathrm{c}$ and $\mathrm{d})$. Although the overall trend in values obtained using the two assays for VIII: Ag was comparable, in some patients discrepant results were obtained (Fig. $1 \mathrm{c}$ and d). In particular, one patient (patient C) had progressive increase in VIII: $\mathrm{Ag}$ and vWF despite clinical and biochemical response to therapy; patient $E$ had a further increase in VIII: $C$, vWF and VIII: Ag after an initial fall on treatment.

Analysis of the complex multimeric structure of factor VIII by crossed immunoelectrophoresis revealed a bell-shaped curve of normal configuration (Fig. 2). No evidence of abnormal migration of the factor VIII: $\mathrm{Ag}$ entering the gel was detected. However, a pre-peak at the origin was noted in 6 of the 7 presentation plasma samples (Fig. 2). This phenomenon was reproducible within individual samples and was not seen in any of the healthy control plasmas handled in identical manner. The height of the pre-peak diminished in subsequent samples in each case. In three of four samples studied, the pre-peak was apparent on crossed immunoelectrophoresis of serum obtained at the same time as plasma was prepared. Dilution of plasmas prior to electrophoresis did not abolish the pre-peak phenomenon. Autoradiography using a specific factor VIII antibody 

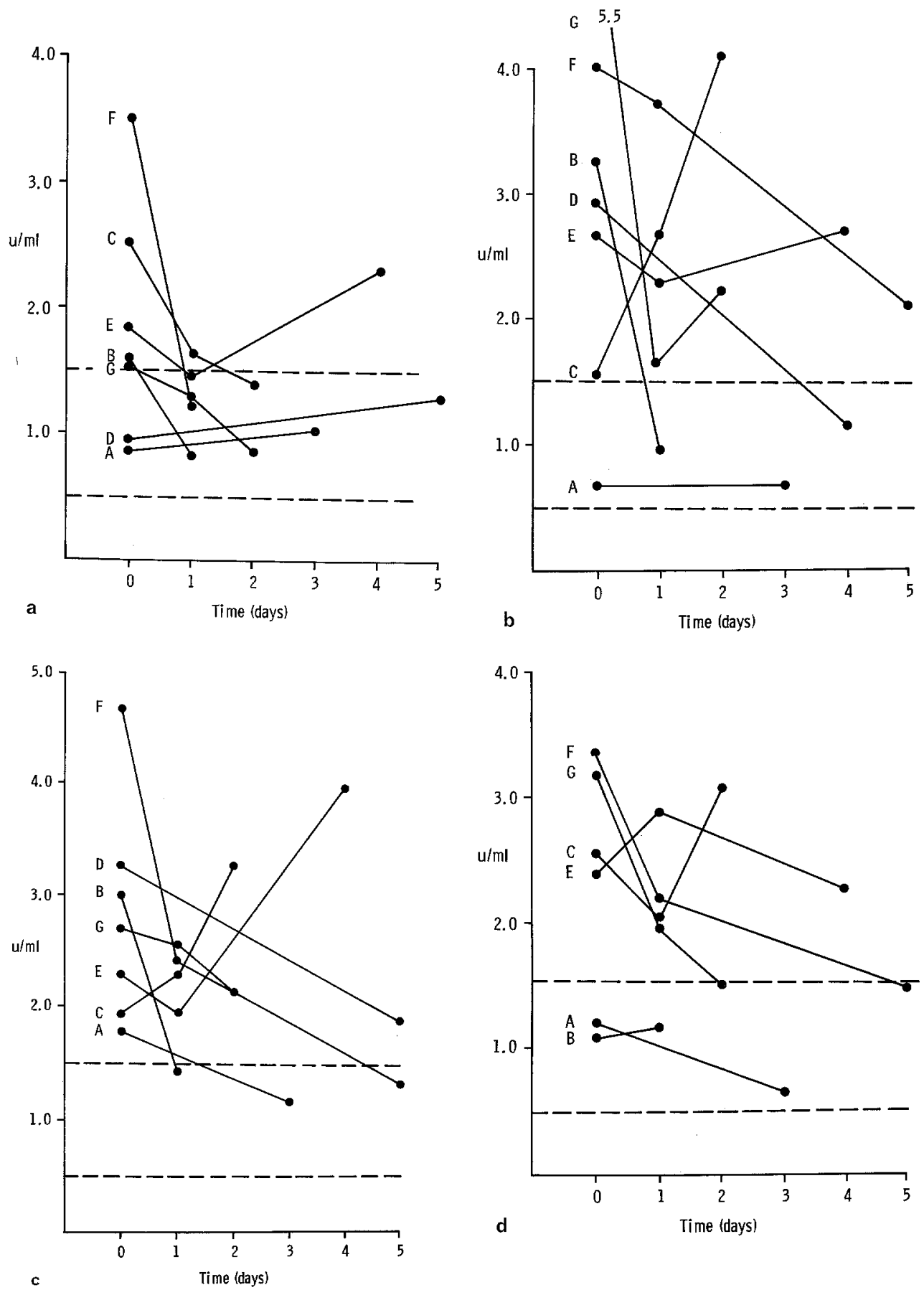

Fig. 1a-d. Plasma concentration of factor VIII during diabetic ketoacidosis (Hatched lines indicate laboratory reference range). a VIII: C; b vWF; c VIII: Ag (Laurell assay); d VIII: Ag (Elisa assay)

confirmed the presence of factor VIII: Ag in the prepeak. No pre-peak was apparent after crossed immunoelectrophoresis of plasma against an antifibronectin antibody. Mulitmeric analysis of plasma from all seven patients (in six of whom a prominent pre-peak was apparent on crossed immunoelectrophoresis) revealed a normal pattern of factor VIII multimers (Fig.3).

\section{Discussion}

We have demonstrated increased plasma concentrations of procoagulant factor VIII, factor VIII-related antigen and von Willebrand factor (measured as risto- cetin co-factor) in the acute phase of diabetic ketoacidosis. The degree of increase was far greater than that which could be attributed to dehydration and reduced plasma volume. Paton [25] has previously found VIII: C and VIII: Ag to be increased in plasma in diabetic ketoacidosis, but serial estimations were not performed and vWF was not measured.

VIII: Ag and vWF are products of vascular endothelial cells, whereas VIII: C is not. Under conditions of health the plasma concentration of the three moieties of the factor VIII complex are similar. However, several conditions are associated with increased plasma factor VIII [26], and it may behave as an acute phase reac- 


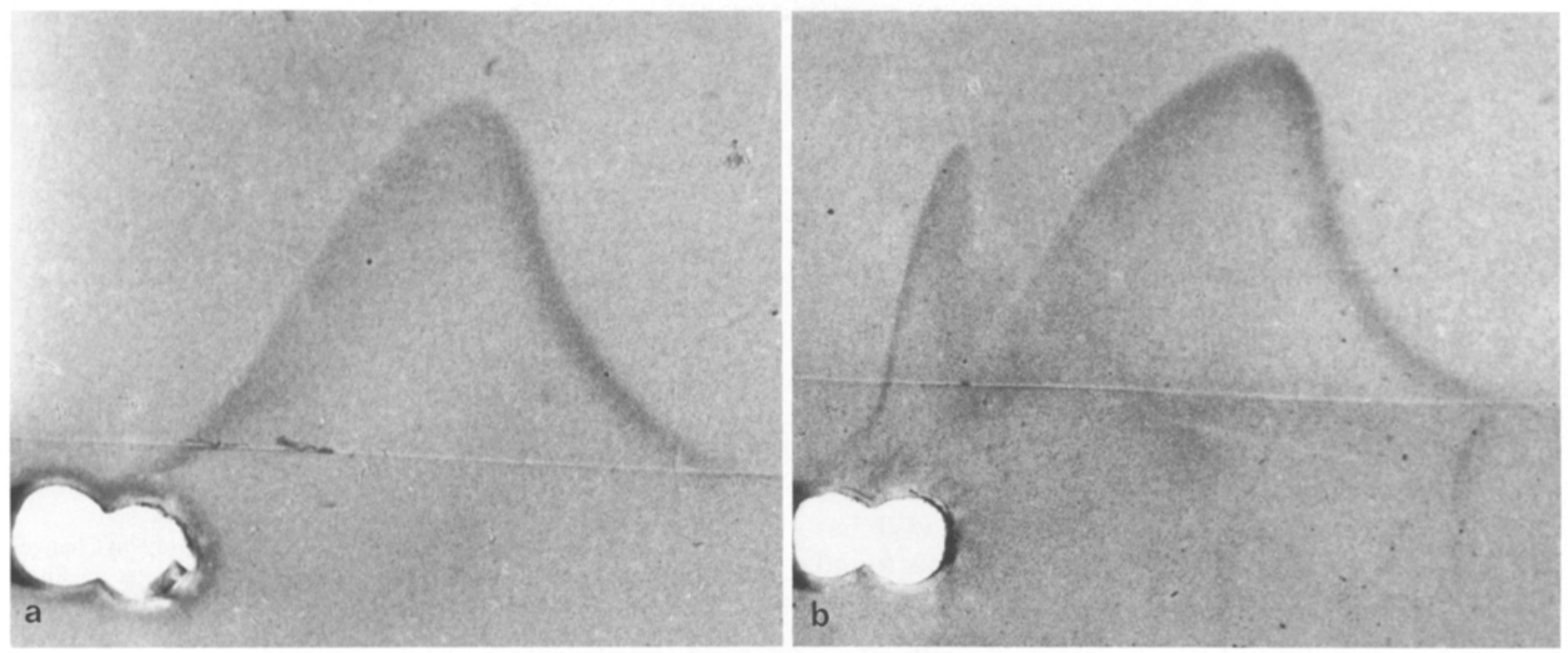

Fig. 2a and b. Crossed immunoelectrophoresis of plasma against antibody to VIII: Ag demonstrating a normal pattern of the main arc and a pronounced pre-peak in the ketoacidotic plasma sample. a Control. b Diabetic

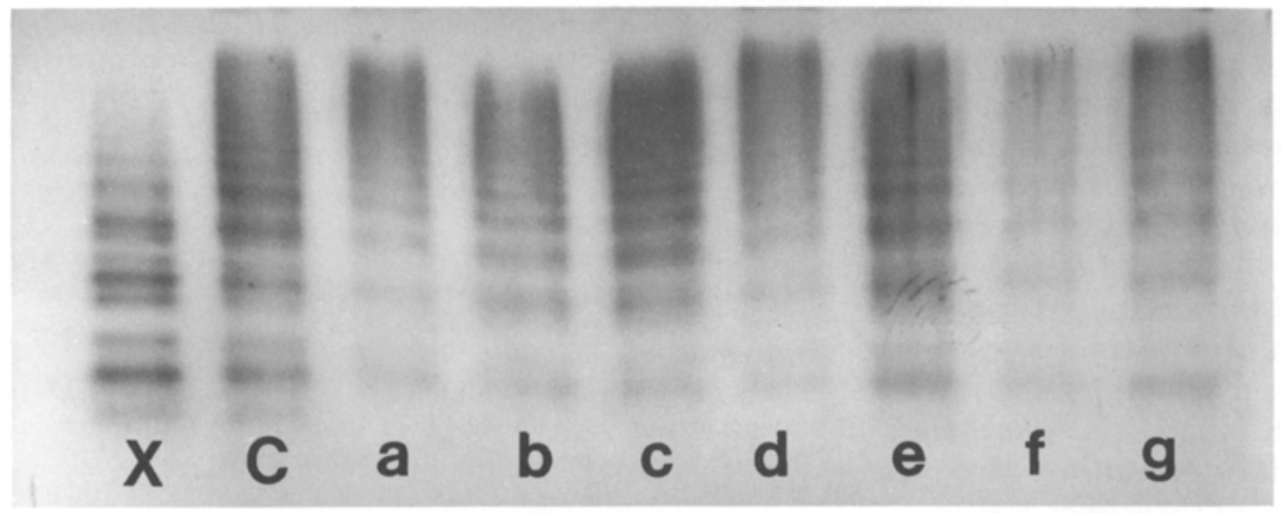

Fig. 3. Multimeric analysis of factor VIII in diabetic plasma. $\mathrm{C}=$ control plasma; $\mathrm{a}$ to $\mathrm{g}=$ plasma from diabetic patients during ketoacidosis; $\mathrm{X}=$ plasma from $\mathrm{a}$ subject with type 2 a von Willebrand's disease (high molecular weight multimers are absent) tant. Alternatively, increases in circulating VIII: $\mathrm{Ag}$ have been considered to represent to presence of endothelial cell damage $[11,14,25]$; particularly striking increases in plasma VIII: Ag have been found in acute respiratory failure, where extensive damage to the pulmonary vascular endothelium may be responsible $[15,16]$. In determining the significance of the observed elevation of factor VIII plasma levels in ketoacidosis, the pattern of the changes is important. The increase of factor VIII: $\mathrm{C}$ and VIII: $\mathrm{Ag}$ which occurs after surgical trauma occurs early (within $24 \mathrm{~h}$ ) but persists for longer than 10 days [26]. This is unlike the pattern of change in diabetic ketoacidosis, where a rapid return toward normal values occurs with clinical and biochemical improvement. The pattern of change of factor VIII in response to treatment was generally consistent, although patients $\mathrm{E}$ and $\mathrm{C}$ behaved rather differently (Fig. 1). It is noteworthy that patient $\mathrm{E}$ was the only subject studied who had extensive diabetic vascular disease (Table 1). Ketoacidosis was complicated by bronchopneumonia in patient $\mathrm{C}$. Patients $\mathrm{E}$ and $\mathrm{C}$ were considerably older than the other subjects studied (Table 1), and had longer duration of diabetes.
The maximum concentration of VIII: $\mathrm{Ag}$ and $\mathrm{vWF}$ achieved was approximately $50 \%$ higher than that of VIII: C (Fig.1); this is consistent with a response to endothelial cell injury, as VIII: $\mathrm{C}$ is not synthesised or stored by vascular endothelium. It is also in accord with the observation that the ability of endothelial cells to synthesise VIII: Ag is enhanced in diabetic patients [27]. However, the possibility also exists that the smaller increase and more rapid fall of plasma VIII: $\mathrm{C}$ is due to the presence of a consumptive coagulopathy, VIII: C being a procoagulant protein which is consumed during fibrin generation; intravascular coagulation is a feature of some cases of diabetic ketoacidosis [25, 28]. Muntean et al. [29] have also described apparent activation of factor VIII in children with poorly controlled diabetes, where the ratio of VIII: $\mathrm{C}$ to its antigen (VIII: CAg) was increased in those patients with poorest glycaemic control.

In order to further investigate the occurrence of endothelial cell damage in ketoacidosis, we sought evidence for the release into the circulation of an abnormal VIII: Ag or vWF. To this end, the complex multimeric structure was assessed by crossed immuno- 
electrophoresis and by electrophoresis through sodium dodecyl sulphate (SDS)-acrylamide, and the plasma concentration of VIII: Ag was assayed by two independent methods and compared with that of VWF measured as ristocetin co-factor. No evidence for any abnormality of factor VIII multimeric structure in diabetic ketoacidosis was found by crossed immunoelectrophoresis, more specific multimeric analysis confirmed this. In addition, values for plasma VWF were comparable to those for VIII: Ag in five patients at presentation. In one other the vWF was markedly increased relative to VIII: $\mathrm{Ag}$, and in a second the reverse situation pertained. The pattern in ketoacidosis is thus unlike that in acute respiratory failure, where a very marked increase in VIII: Ag with only modest or no increase in vWF has been found [16]. Generally, good agreement was found in plasma VIII: Ag concentrations assayed by the two methods, but some exceptions were noted (Fig.1, patients A and B). Although no evidence for the production of an abnormal factor VIII in most cases of ketoacidosis was detected by the methods used, the presence of a pre-peak on crossed immunoelectrophoresis is a novel and interesting finding. The material staining as a prepeak contains factor VIII: Ag as demonstrated by autoradiography. It thus represents residual VIII: Ag which has failed to migrate from the well in the first dimension. This phenomenon has been described in other situations, including pregnancy, the post-transfusional state [30] and in acute respiratory failure [16], and can be induced in plasma by heat treatment or cryoprecipitation [31]. Although it has been suggested that the prepeak is an artefact of the electrophoretic system employed [32, 33], our results and those of Miller et al. [31] render this unlikely. We have confirmed that the appearance of a pre-peak is a non-random phenomenon, being present in six of seven ketoacidotic plasma samples, reproducible within these samples and diminishing with clinical improvement. The phenomenon was also detected on electrophoresis of serum, and is thus unlikely to be due simply to fibrin formation ex vivo. In addition, the peak does not contain material reacting with an antibody to fibronectin. It seems that the presence of a pre-peak of VIII: Ag on crossed immunoelectrophoresis is a feature of the diabetic ketoacidotic state, and it may relate to the increased concentration of VIII: Ag in plasma, possibly representing aggregated VIII: Ag [31]. Such aggregates may not form in the different buffer system, which includes SDS, used for multimeric analysis.

In summary, elevated plasma factor VIII is a feature of diabetic ketoacidosis. The relatively greater increase in VIII: Ag and vWF is consistent with the presence of entothelial cell damage, although no other supporting evidence for this was found. The frequent presence of a pre-peak of VIII: Ag on crossed immunoelectrophoresis, possibly representing aggregated VIII: $\mathrm{Ag}$, is a novel finding in ketoacidosis.

\section{References}

1. Bensoussan D, Levy-Toledano S, Passa P, Caen J, Canivet J (1975) Platelet hyperaggregation and increased plasma levels of von Willebrand factor in diabetics with retinopathy. Diabetologia 11: 307-312

2. Borkenstein MH, Muntean WE (1982) Elevated factor VIII activity and factor VIII-related antigen in diabetic children without vascular disease. Diabetes 31: 1006-1009

3. Brooks AMV, Hussein S, Chesterman CN, Martin JF, Alford FP, Penington DG (1983) Platelets, coagulation and fibrinolysis in patients with diabetic retinopathy. Thromb Haemost 49: 123-127

4. Coller BS, Frank RN, Milton RC, Gralnick HR (1978) Plasma cofactors of platelet function: correlation with diabetic retinopathy and hemoglobins $\mathrm{A}_{1 \mathrm{a}-\mathrm{c}}$. Ann Int Med 88: 311-316

5. Fuller JH, Keen H, Jarret RJ, Omer T, Meade TW, Chakrabarti R, North WRS, Stirling Y (1979) Haemostatic variables associated with diabetes and its complications. Br Med J 2: 964-966

6. Gensini GF, Abbate R, Favilla S, Neri Serneri GG (1979) Changes of platelet function and blood clotting in diabetes mellitus. Thromb Haemost 42: 983-993

7. Gonzalez J, Colwell JA, Sarji KE, Nair RMG, Sagel J (1980) Effect of metabolic control with insulin on plasma von Willebrand factor activity (VIII R/vWF) in diabetes mellitus. Thromb Res 17: 261-266

8. Lufkin EG, Fass DN, O'Fallon WM, Bowie EJW (1979) Increased von Willebrand factor in diabetes mellitus. Metabolism 28:63-66

9. Odegaard AE, Skalhegg BA, Hellen AJ (1964) Increased activity of "anti-Willebrand factor" in diabetic plasma. Thromb Diath Haemorrh 11:27-37

10. Pandolfi M, Almir LO, Holmberg L (1974) Increased von Willebrand antihemophilic factor $\mathrm{A}$ in diabetic retinopathy. Acta Ophthalmol 52: 823-828

11. Porta M, Townsend C, Clover GM, Nanson M, Alderson AR, McCraw A, Kohner EM (1981) Evidence for functional endothelial cell damage in early diabetic retinopathy. Diabetologia 20: 597-601

12. Rak K, Beck P, Udvardy M, Pfliegler G, Misz M, Boda Z (1983) Plasma levels of beta-thromboglobulin and factor VIII-related antigen in diabetic children and adults. Thromb Res $29: 155-162$

13. van Oost BA, Veldhuyzen BFC, van Houwelingen HC, Timmermans APM, Sixma JJ (1982) Tests for platelet changes, acute phase reactants and serum lipids in diabetes mellitus and peripheral vascular disease. Thromb Haemost 48: 289-293

14. Boneu B, Abbal M, Plante J, Bierme R (1975) Factor-VIII complex and endothelial damage. Lancet 1: 1430

15. Grant K, Rodvien R, Mielke CH (1978) Altered factor VIII complexes in patients with acute respiratory insufficiency. Thromb Haemost 40: 326-334

16. Carvalho ACA, Bellman SM, Saullo VJ, Quinn D, Zapol WM (1982) Altered factor VIII in acute respiratory failure. $\mathbf{N}$ Engl $\mathbf{J}$ Med 307: 1113-1119

17. Biggs R, Eveling J, Richards G (1955) The assay of antihaemophilic globulin activity. $\mathrm{Br}$ J Haematol 1: 20-24

18. Evans RJ, Austen DEG (1977) Assay of ristocetin co-factor using fixed platelets and a platelet counting technique. $\mathrm{Br} \mathrm{J}$ Haematol $37: 289-294$

19. Laurell CB (1965) Antigen-antibody crossed electrophoresis. Ann Biochem 10:358-361

20. Short PE, Williams CE, Picken AM, Mill FGH (1982) Factor VIII related antigen: an improved enzyme immunoassay. Med Lab Sci 39: 351-355

21. Reay $\mathbf{P}$ (1982) Use of $\mathrm{N}$-bromosuccinimide for the iodination of proteins for radioimmunoassay. Ann Clin Biochem 19: 129-133

22. Ball J, Malia RG, Greaves M, Preston FE (1986) Demonstration of abnormal factor VIII multimers in acquired von Willebrand's disease associated with a circulating inhibitor. $\mathrm{Br} \mathrm{J}$ Haematol (in press)

23. Ruggeri ZM, Zimmerman TS (1980) The complex multimeric composition of factor VIII/von Willebrand factor. Blood 57 : $1140-1143$ 
24. Enayat MS, Hill FGH (1983) Analysis of the complexity of the multimeric structure of factor VIII related antigen/von Willebrand protein using a modified electrophoretic technique. J Clin Pathol 36: 915-919

25. Paton RC (1981) Haemostatic changes in diabetic coma. Diabetologia 21: $172-177$

26. Brozovic M (1977) Physiological mechanisms in coagulation and fibrinolysis. Br Med Bull 33: 231-236

27. Giustolisi R, Musso R, Russo M, Catania N, Lombardo T, Cacciola E (1982) Possible evidence for an increased factor VIII antigen synthesis in vascular endothelium of diabetic subjects. Thromb Haemost 47:293

28. Timperley WR, Preston FE, Ward JD (1974) Cerebral intravascular coagulation in diabetic ketoacidosis. Lancet 1:952-956

29. Muntean WE, Borkenstein MH, Haas J (1985) Elevation of factor VIII coagulant activity over factor VIII coagulant antigen in diabetic children without vascular disease. A sign of activation of the factor VIII coagulant moiety during poor diabetes control. Diabetes 34: 140-144

30. Bowie EJW, Fass DN (1979) Factor VIII-related antigen (VIII $\mathrm{RAg}$ ) in haemophilic patients and in carriers. Lancet $2: 1049-1050$
31. Miller $\mathrm{CH}$, Hilgartner MW, LeStrange RC, McLaughlin GW (1982) Factor VIII-related antigen pre-peak on crossed immunoelectrophoresis: A non-random phenomenon. Thromb Res 25: 101-107

32. Girolami A, Sticchi A, Cappellato G, Quaino V (1980) Factor VIII antigen pre-peak. Lancet 1: 264-265

33. Howard MA, Perkin J, Koutts J (1980) Factor VIII antigen prepeak. Lancet 1: 715

Received: 15 May 1986

and in revised form: 16 January 1987

\section{Dr. M. Greaves}

Department of Haematology

Royal Hallamshire Hospital

Glossop Road

Sheffield S10 2JF

UK 